\title{
"Knowledge, Attitude and Practice of Type 2 Diabetic Patients Visiting Diabetic OPD of TUTH and Non Diabetic Population of Kathmandu"
}

\author{
Sapkota Yogita ${ }^{1}$ \\ Department of Nutrition and Dietetics, Central Campus of Technology, Institute of Science and \\ Technology, Tribhuvan University, Hattisar, Dharan, Nepal
}

\begin{abstract}
Introduction: Diabetes Mellitus is a major lifestyle disorder disease which is further expanded due to ignorance and lack of knowledge. This study was carried out to assess the Knowledge(K), Attitude (A) and Practice (P)-KAP among diabetic patients visiting diabetic OPD of Tribhuvan University Teaching Hospital (TUTH) and nondiabetic population residing in Kathmandu, Nepal and compare KAP with each other's.
\end{abstract}

Methods: A cross-sectional survey design was used to assess KAP of both 90 diabetic and 90 nondiabetic population and associated factors via interview administered Questionnaire.

Results: Among diabetic population, it was found that, the mean \pm SD Knowledge, Attitude and Practice score was $12.97 \pm 5.682,3.28 \pm 1.805$ and $11.87 \pm 4.604$ respectively. $60 \%, 70 \%$ and $47.8 \%$ of diabetic participants had good knowledge, attitude and practice scores respectively. A significant association was found between KAP score and education level of the patient and with Physical Activity level of the patient. No significant association was found between KAP score and Age group and with genetic history of the patient. Among non-diabetic population, it was found that, the mean \pm SD Knowledge, Attitude and Practice score was $10.89 \pm 4.496,3.31 \pm 1.605$ and $7.46 \pm 3.098$ respectively. $40 \%, 73.3 \%$ and $51.1 \%$ of the non-diabetic participants had good knowledge, attitude and practice scores respectively. Significant difference between the mean knowledge score of diabetic and non-diabetic group $(\mathrm{P}<0.05, \mathrm{P}=0.007)$ was found but no significant difference between the mean attitude score of diabetic and non-diabetic group $(\mathrm{P}>0.05, \mathrm{P}=0.896)$ was found.

Conclusions: Overall, this study revealed good knowledge, good attitude but poor practice among diabetic group. In contrary poor knowledge but good attitude and poor lifestyle practices was found among non-diabetic group.Therefore, need based awareness programs and educational interventions targeting both diabetic and non-diabetic population should be developed and launched.

Key Words: Attitude ;Diabetes Mellitus; Disorder; Knowledge; Lifestyle; Practice

\section{Introduction}

The prevalence of diabetes is increasing worldwide due to change in life style and growing number of aging population. It is clear that diabetes imposes a heavy disease burden in both developed and developing countries with the consumption of

Corespondence Address: Yogita Sapkota, Dietician, National Hospital and Cancer Research Center, Jaulakhel, Lalitpur. Email address: yogita.sapkota07@gmail.com energy dense diet and inactive lifestyle. ${ }^{1}$

The problem is further expanded due to ignorance and lack of knowledge. Regarding the level of awareness, obtaining information about diabetes in a population is the prior step in formulating a prevention program for diabetes. A very few hospital based studies have been done on knowledge regarding diabetes mellitus among diabetic patients in Nepal. This study is expected to reveal the gap 
of knowledge that needs to be reinforced, thereby providing data for formulating prevention programs for diabetes. If the characteristic of the patients in terms of knowledge, their attitude and practices about diabetes is known, education is likely to be effective.

The general objective of the study is to investigate the knowledge, attitude and practice of Type 2 diabetic patients visiting diabetic OPD of TUTH and non-diabetic population of Kathmandu.

The specific objectives are:

a) To assess knowledge, attitude and practices of the Type 2 diabetic patients visting diabetic OPD of TUTH, Kathmandu.

b) To assess knowledge, attitude and practices of the non-diabetic population of Kathmandu.

c) To compare the knowledge and attitude of Type 2 diabetic patients with the knowledge and attitude of non-diabetic population.

\section{Methods}

A cross-sectional descriptive study was conducted among the diabetic patients attending the diabetic outpatient department (OPD) of Tribhuvan University Teaching Hospital(TUTH), Maharajgunj and among the non-diabetic population of different places of Kathmandu to assess the information on knowledge, attitude and practices on Type 2 Diabetes Mellitus. The study population was Type 2 Diabetic patients visiting the diabetic OPD of TUTH and also the general population not having diabetes mellitus, from various places of Kathmandu who were the usual resident of the Kathmandu valley at the time of study Inclusion Criteria includes Type 2 Diabetic patients (physician diagnosed case) and General population not having diabetes mellitus . Exclusion Criteria includes Type1 diabetes mellitus (physician, diagnosed case), Gestational diabetes patients (physician, diagnosed case) and participants who did not consent to participate in the study

The study variables were classified into two categories: Dependent variable: Knowledge, Attitude and Practice (KAP) score of diabetic patient. It is defined by Poor KAP score $<28$ and Good KAP score $\geq 28$. Independent variable: Education level of diabetic patient, Age of diabetic patient, Physical activity level of diabetic patient, Genetic history of diabetic patient.

The samples of respondents were selected by purposive and convenient sampling method. All the diabetic patients visiting diabetic OPD of TUTH during the period of one and half month from April 4 to May 14, 2017 were selected using the purposive sampling method and enrolled in this study. For the population with no diabetes, samples were taken by convenient sampling method. ${ }^{2}$ Five different places of Kathmandu were selected using convenient sampling method and samples of nondiabetic participants were selected by convenient method from those different places.

The sample size was determined by using formula assuming the prevalence rate of type 2 diabetes is to be $25 \%$ in the urban area $1,95 \%$ confidence interval, $9 \%$ margin of error (D). The sample size was calculated to be $89 \approx 90$. For the comparison, equal number of samples were taken for nondiabetic population i.e 90. So the total number of samples taken was 180 .

The KAP Questionnaire was adapted from the questionnaire prepared by ASTHA Nepal and modified as requirement. (ASTHA Nepal is an NGO working for diabetes. It has used a questionnaire to assess KAP of diabetic patients as a part of awareness program)

The processed data was then entered and analyzed by using the Microsoft Excel and SPSS version 20. Data interpretation was done with descriptive statistics. Percentage, frequency, mean and standard deviation was used to describe the demographic variables, level of knowledge, attitude towards the disease and their practices. Chi-square test was used to find the association between knowledge, attitude and practice score with age, physical activity level, education level and family history. Test of significance were performed using independent 
sample t-test to compare means among groups of different variables. All significance tests were two tailed, $\mathrm{P}<0.05$ was considered statistically significant.

\section{Results}

Socio-demographic characteristics of the participants were determined. Among the 90 type 2 diabetic patients who were enrolled in the study, majority of the patients were from age group 50-59. The minimum age of the patient was 27 whereas the maximum age of the patient was 82 . The mean \pm std. deviation age of the diabetic patients was found to be $51.69 \pm 12.356$.

Among the 90 non-diabetic population who were enrolled in the study, majority of them were from age group 30-39. The minimum age of the person was 27 whereas the maximum age of the patient was 67 . The mean \pm std. deviation age of the diabetic patients was found to be $41.09 \pm 9.309$. Among 90 diabetic population, majority of the participants in the study were female i.e. $46(51.1 \%)$ as compared to male 44(48.9\%).Similarly for non-diabetic population, $50 \%$ male and $50 \%$ female were taken. Among 90 diabetic population 18(21.1\%) were illiterate that is never gone to school and cannot read and write. For non-diabetic population, $6(6.7 \%)$ were illiterate.
The Knowledge, attitude and practice of participants were assessed. 60\% (majority), 70\% (majority) and $47.8 \%$ (minority) of the diabetic participants had good knowledge, attitude and practice scores respectively.

A significant relationship existed between total KAP score and education level of the patient and with Physical Activity level of the patient. No significant relationship existed between total KAP score and Age group and with genetic history of the patient. $40 \%$ (minority), $73.3 \%$ (majority) and $51.1 \%$ (majority) of the non-diabetic participants had good knowledge, attitude and practice scores respectively. From diabetic population, what we found was, the mean \pm SD Knowledge, Attitude and Practice score was $12.97 \pm 5.682,3.28 \pm 1.805$ and $11.87 \pm 4.604$ respectively. From non-diabetic population, we found, the mean \pm SD Knowledge, Attitude and Practice score was 10.89 $\pm 4.496,3.31$ \pm 1.605 and $7.46 \pm 3.098$ respectively. There was significant difference between the mean knowledge score of diabetic and non-diabetic group $(\mathrm{P}<0.05$, $\mathrm{P}=0.007)$. There was no any significant difference between the mean attitude score of diabetic and nondiabetic group $(\mathrm{P}>0.05, \quad \mathrm{P}=0.896)$. Table 1.shows the comparison of knowledge and attitude scores among two groups.

\begin{tabular}{|l|c|c|c|c|c|c|}
\hline \multicolumn{1}{|c|}{$\begin{array}{c}\text { Study } \\
\text { group }\end{array}$} & $\begin{array}{c}\text { Mean } \\
\text { Knowledge } \\
\text { Score }\end{array}$ & $\begin{array}{c}\text { Std. } \\
\text { deviation }\end{array}$ & $\begin{array}{c}\text { P } \\
\text { Value }\end{array}$ & $\begin{array}{c}\text { Mean } \\
\text { attitude } \\
\text { Score }\end{array}$ & $\begin{array}{c}\text { Std. } \\
\text { deviation }\end{array}$ & Value \\
\hline $\begin{array}{l}\text { Diabetic } \\
\text { group }\end{array}$ & 12.97 & 5.682 & $0.007^{*}$ & 3.28 & 1.605 & 0.896 \\
\hline $\begin{array}{l}\text { Non- } \\
\text { diabetic } \\
\text { group }\end{array}$ & 10.89 & 4.496 & & 3.31 & 1.805 & \\
\hline
\end{tabular}

Statistically significant: $P$ value $<0.05 *$

Table 1: Comparison of mean scores of both groups

There was significant difference between the mean knowledge score of diabetic and non-diabetic group $(\mathrm{P}<\mathbf{0 . 0 5}, \mathrm{P}=\mathbf{0 . 0 0 7})$ There was no any significant difference between the mean attitude score of diabetic and non-diabetic group $(\mathrm{P}>0.05, \mathrm{P}=\mathbf{0 . 8 9 6})$. Factors associated with 


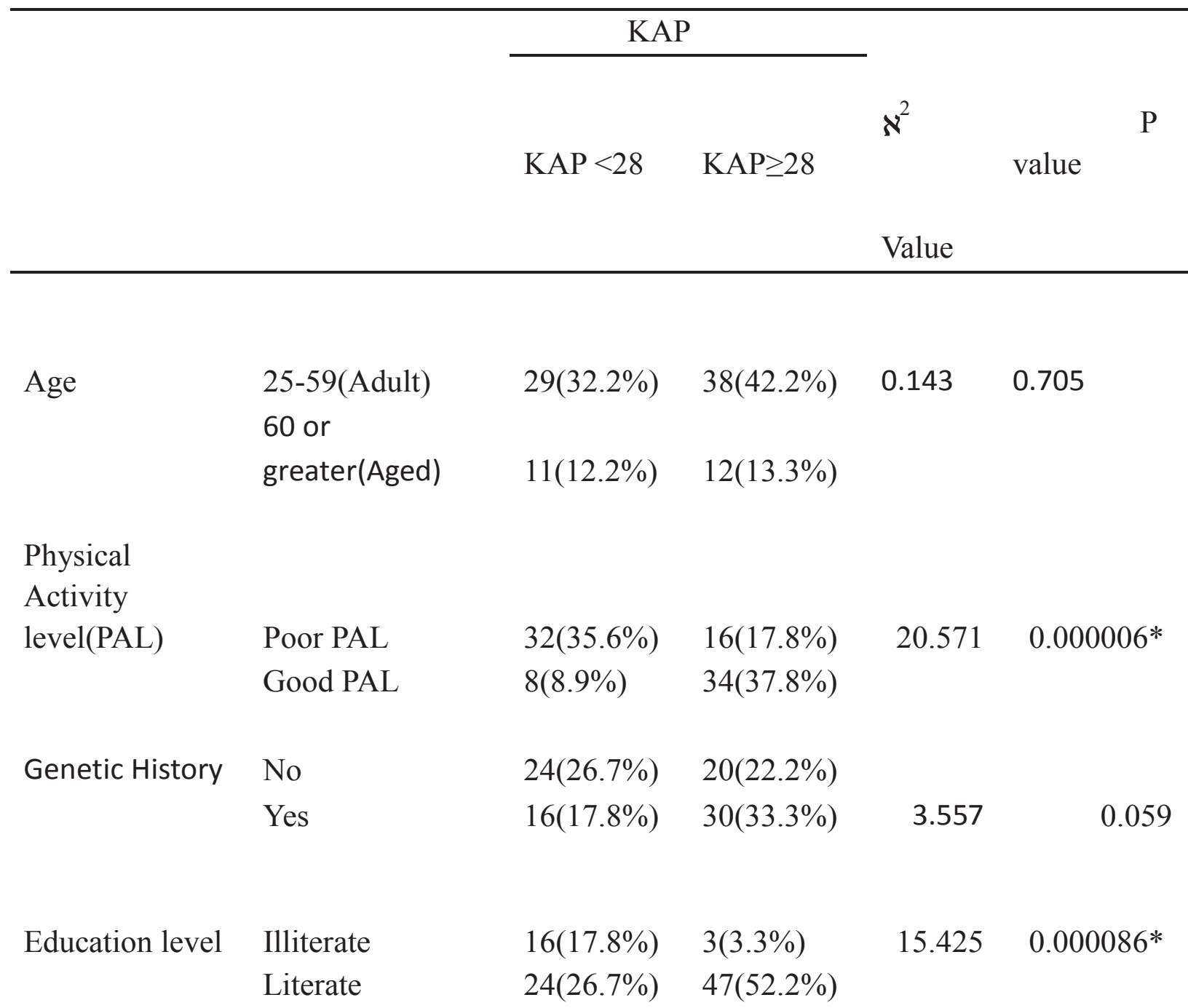

Statistically significant: $\mathrm{P}$ value $<0.05^{*}$

Table 2: Factors associated with KAP score of diabetic patient

\section{Discussion}

Here, our study revealed a good level of knowledge and attitude but poor level of practice score in diabetic population. Similarly, a poor level of knowledge and practice score but a good level of attitude score of non-diabetic population was explored . Some studies reported that diabetic patients had good level of diabetes related knowledge which supports our study. Similar studies conducted in Andhra Pradesh (India), Sri Lanka and Malaysia also showed satisfactory diabetes knowledge in diabetic patients, 34 . Result similar to what our study revealed, was shown by another KAP study done at Jammu, India where knowledge of diabetic 
patients was good but attitude and practices needed improvement. $^{5}$

Our study finding showed the good level of attitude, which is supported by other studies from urban area of South India and UAE, reported the findings that there is positive and good level of attitude among diabetic patients. ${ }^{6}$ The poor level of practice was shown by our study which is further supported by another similar study conducted in Pakistan. ${ }^{2}$ Here, we found that diabetic patients had good attitude score. Thus, we can say that their good knowledge level might have affected their attitude level and say there is some association between knowledge and attitude of the patient which is proved in other studies. ${ }^{7}$ Improving knowledge of the people can improve their attitude towards diabetes and in the long run change their practices to embrace healthier lifestyles such as eating healthy foods, and engaging in physical activity. ${ }^{8}$

Since in this study, diabetic patients have good knowledge and good attitude about care of diabetes but lack of proper practice towards its implementation. So, we can conclude that factors beyond knowledge and attitude contribute to disease management. Plausible factors could be poor self-management, lack of motivation, inadequate social support or lack of resources that are necessary for sustained life style modification or behavior change. ${ }^{9}$ Cultural influences also have interfered with successful diabetes selfmanagement. ${ }^{10}$ The poor perceptions might have reinforced unhealthy dietary habits even though people are aware of the relationship between these practices and chronic diseases such as diabetes. ${ }^{11}$ A patient/self-empowerment approach to diabetes care may enhance the efficiency of DM prevention and control programs in countries like Nepal that experience DM as a major public health problem. ${ }^{12}$ This gap between knowledge and practice could be due to lack of motivation to apply the knowledge into action or practice and conservative thoughts with over confidence. ${ }^{13}$
Similarly, what we found is that the poor knowledge and practice among non-diabetic population, so Diabetic mellitus health education should put greater emphasis on prevention of diabetes mellitus among the healthy adults as well. Poor practice or habits indicates that the healthy population of today have risk of becoming diabetic in future. One possible reason for not performing well in knowledge section by non-diabetic population is might be due to lack of emphasis on explanation of basic pathogenesis of diabetes mellitus to the non-diabetic or it might be because on-going public health promotion activity and awareness program about diabetes has not reached the general community.

One of the interesting fact that is revealed from this study is that, despite of the poor mean practice score, when we see in overall, majority percentage of the non-diabetic population i.e more than $50 \%$ of the population had good practice scores. The plausible justification can be that, in our study, majority of the non-diabetics belonged to service holders thus we can say, the service holders i.e government and private employees are better educated and have greater contact with education materials.

Tham et al compared the knowledge of patients with and without diabetes in an emergency department and found that the knowledge was not statistically significantly different in these two groups $(68.1 \%$ and $65.9 \%$ respectively). ${ }^{14}$ Our study in contrast showed that patients with diabetes outperformed significantly $(\mathrm{p}<0.05)$ patients without diabetes, $51.88 \%$ versus $43.56 \%$ (12.97 versus 10.89 (Mean knowledge score). Our result is supported by another comparative study done in Malaysia where Patients with diabetes had higher overall knowledge scores than those without diabetes $(81.8 \%$ vs $64 \%$, $\mathrm{p}<0.001) .{ }^{15}$

One possible explanation was that many of our patients with diabetes were actually having some of the micro vascular and macro vascular complications and received regular counselling organized by the diabetic counseling OPD and also 
bi-weekly diabetic health education organized by the TUTH, Department of Endocrinology. Another important fact that has been revealed from this study is that, majority of the diabetics are from education level 6-slc and among non-diabetics, majority belonged to masters level. Inspite of this fact, what we found that there is significant difference between the mean knowledge score among two groups. The probable reason might be that the diabetic population were receiving regular bi-weekly diabetic health education organized in the hospital.

Our study explored the relation between KAP and PAL. There was significant correlation between the KAP and Physical activity level of the patient $(\mathrm{P}<0.05)$. This is supported by another study which showed that the relative probability of having a highly satisfactory level of knowledge was 7.53 times higher among those who did physical activities than those who did not do physical activities. Similarly it showed that the relative probability of having a highly satisfactory level of practice was 3.74 times higher among those who did physical activities than those who did not do physical activities. ${ }^{13}$ Similarly significant correlation was found between education level of the patient and KAP of the patient. There is common assumption that education level of the people would have adequate KAP score for control of DM and our study is supporting this. Significant association in level of knowledge to age, education and family history of diabetes was reported in one study conducted in Nepal. ${ }^{13}$ Similar study conducted in Kathmandu also supports this as it showed significant relationship between knowledge of the patient and education level of the patient ${ }^{4}$. But in case of relation with age and family history, we have got contradictory findings. There was found no any significant relationship between age of the patient and KAP of the patient. Thus we can say KAP of person does not depend upon his/ age or age does not effect on KAP of patient.

No significant correlation was there between Genetic history of the patient and KAP $(\mathrm{P}>0.05)$ and similar study conducted in Kathmandu had given contradictory findings ${ }^{4}$. Thus we can thus say that if a person has diabetic family history it does not necessarily mean that he/she should have good knowledge, attitude and practice about diabetes. Other factors might have been contributing on this. Most studies on the knowledge, attitude and practices of diabetes done in Nepal and elsewhere target patients with diabetes. Unlike these, this study targeted the general population also. We therefore lack adequate comparative data for community and our discussions are mostly based on knowledge, attitude and practices of people with diabetes who in most cases have better exposure to diabetes education. Similarly, there is difficulty in comparing our findings with studies from other countries as there is disparity between the characteristics of the study population and study tools used in other studies.

\section{Conclusions}

Factors beyond knowledge and attitude contribute to disease management. Plausible factors could be poor self-management, lack of motivation, inadequate social support or lack of resources that are necessary for sustained life style modification or behavior change. Cultural influences also have interfered with successfuldiabetesself-management. A patient/self-empowerment approach to diabetes care may enhance the efficiency of DM prevention and control programs in countries like Nepal that experience DM as a major public health problem. Poor practice or habits indicates that the healthy population of today have risk of becoming diabetic in future.

\section{Acknowledgement}

I would like to acknowledge Mr. Milan Dhakal and Miss Nanishova Shakya for providing me their intellectual thoughts during this research and also Mr. Pratik Niraula for helping me on citations.

\section{Conflict of Interest}

Not any 


\section{References}

1. M.R. Chhetri, Champan RS. Prevalence and determinants of diabetes among the elderly population in the Kathmandu Valley of Nepal. Nepal medical college journal. 2009;11(1):5.

2. Gul N. Knowledge, attitudes and practices of type 2 diabetic patients. Journal of Ayub Medical College, Abbottabad : JAMC. 2010;22(3):128-31.

3. Perera DP, De Silva RE, Perera WL. Knowledge of diabetes among type 2 diabetes patients attending a primary health care clinic in Sri Lanka. Eastern Mediterranean health journal $=$ La revue de sante de la Mediterranee orientale $=$ al-Majallah al-sihhiyah li-sharq al-mutawassit. 2013;19(7):644-8.

4. N. Shrestha, S.B. Yadav, AM Joshi, BDP Patel, J Shrestha, Bharkher D. Diabetes knowledge and assosiated factors among diabetes patient in central Nepal. International journal of collaborative research on internal medicine and public health. 2015;7(5).

5. RK Gupta, TN Shora, R Jan, SK Raina, V Mengi, Khajuria V. Knowledge attitude and practices in type 2 diabetes milletus patients in rural northern India. Indian journal of community health. 2015;27(3).

6. Al-Maskari F, El-Sadig M, Al-Kaabi JM, Afandi B, Nagelkerke N, Yeatts KB. Knowledge, attitude and practices of diabetic patients in the United Arab Emirates. PloS one. 2013;8(1):e52857.

7. Baradaran HR, Knill-Jones RP, Wallia S, Rodgers A. A controlled trial of the effectiveness of a diabetes education programme in a multi-ethnic community in Glasgow [ISRCTN28317455]. BMC public health. 2006;6:134.

8. JJ Gagliardino, C Gonzalez, JE Caporale. The diabetes related attitudes of health care professionals and persons with diabetes in Argentina. Rev Panam Salud Publica. 2007;22(5).

9. HN Shu, KH Chan, ZY Lian, YH Chuah, AN Waseem, A Kadirvelu. Reality vs Illusion : Knowledge attitude and practice among diabetic patients. International journal of collaborative research on internal medicine and public health. 2012;4(5).

10. G Kishokanth, S Prathapan, J Indrakumar, Joseph J. Factors influencing self management of diabetes melliteus; a review article. Journal of diabetology. 2013;4(3):6.

11. Greenhalgh T, Helman C, Chowdhury AMm. Health beliefs and folk models of diabetes in British Bangladeshis: a qualitative study. BMJ : British Medical Journal. 1998;316(7136):978-83.

12. Kalra S, Sridhar GR, Balhara YPS, Sahay RK, Bantwal G, Baruah MP, et al. National recommendations: Psychosocial management of diabetes in India. Indian Journal of Endocrinology and Metabolism. 2013;17(3):376-95.

13. Gautam A, Bhatta DN, Aryal UR. Diabetes related health knowledge, attitude and practice among diabetic patients in Nepal. BMC endocrine disorders. 2015;15:25.

14. Tham KY, Ong JJ, Tan DK, How KY. How much do diabetic patients know about diabetes mellitus and its complications? Annals of the Academy of Medicine, Singapore. 2004;33(4):503-9.

15. Ding CH, Teng CL, Koh CN. Knowledge of diabetes mellitus among diabetic and non-diabetic patients in Klinik Kesihatan Seremban. The Medical journal of Malaysia. 2006;61(4):399-404. 